\title{
Surgical management of moderate adolescent idiopathic scoliosis with a fusionless posterior dynamic deformity correction device: interim results with bridging 5-6 disc levels at 2 or more years of follow-up
}

\author{
Yizhar Floman, MD, ${ }^{1}$ Ron El-Hawary, MD, MS, ${ }^{2}$ Michael A. Millgram, MD, ${ }^{1}$ Baron S. Lonner, MD, ${ }^{3}$ \\ and Randal R. Betz, MD4
}

\begin{abstract}
${ }^{1}$ Israel Spine Center, Assuta Hospital, Tel Aviv, Israel; " IWK Health Centre Halifax, Nova Scotia, Canada; ${ }^{3 M o u n t}$ Sinai Hospital Icahn School of Medicine, New York, New York; and ${ }^{4}$ Institute for Spine \& Scoliosis, Lawrenceville, New Jersey
\end{abstract}

\begin{abstract}
OBJECTIVE A posterior dynamic deformity correction (PDDC) system was used to correct adolescent idiopathic scoliosis (AIS) without fusion. The preliminary outcomes of bridging only 3-4 discs in patients with variable curve severity have previously been reported. This paper examines a subgroup of patients with the authors' proposed current indications for this device who were also treated with a longer construct.
\end{abstract}

METHODS Inclusion criteria included a single AIS structural curve between $40^{\circ}$ and $60^{\circ}$, curve flexibility $\leq 30^{\circ}, \operatorname{PDDC}$ spanning 5-6 levels, and minimum 2-year follow-up. A retrospective review was conducted and demographic and radiographic data were recorded. A successful outcome was defined as a curve magnitude of $\leq 30^{\circ}$ at final follow-up. Any serious adverse events and reoperations were recorded.

RESULTS Twenty-two patients who met the inclusion criteria were operated on with the PDDC in 5 medical centers. There were 19 girls and 3 boys, aged 13-17 years, with Risser grades $\geq 2$. Thirteen had Lenke type 1 curves and 9 had type 5 curves. The mean preoperative curve was $47^{\circ}$ (range $40^{\circ}-55^{\circ}$ ). At a minimum of 2 years' follow-up, the mean major curve measured $25^{\circ}(46 \%$ correction, $p<0.05)$. In $18(82 \%)$ of 22 patients, the mean final Cobb angle measured $\leq 30^{\circ}$ (range $15^{\circ}-30^{\circ}$ ). Trunk shift was corrected by $1.5 \mathrm{~cm}$ (range $0.4-4.3 \mathrm{~cm}$ ). The mean minor curve was reduced from $27^{\circ}$ to $17^{\circ}$ at final follow-up ( $35 \%$ correction, $p<0.05$ ). For Lenke type 1 patterns, the mean $2 \mathrm{D}$ thoracic kyphosis was $24^{\circ}$ preoperatively versus $27^{\circ}$ at final follow-up $(p<0.05)$, and for Lenke type 5 curves, mean lumbar lordosis was $47^{\circ}$ preoperatively versus $42^{\circ}$ at final follow-up $(p<0.05)$. The mean preoperative Scoliosis Research Society-22 questionnaire score improved from $2.74 \pm 0.3$ at baseline to $4.31 \pm 0.4$ at 2 years after surgery $(p<0.0001)$. The mean preoperative self-image score and satisfaction scores improved from preoperative values, while other domain scores did not change significantly. Four patients (18\%) underwent revision surgery because of nut loosening $(n=2)$, pedicle screw backup $(n=1)$, and ratchet malfunction $(n=1)$.

CONCLUSIONS In AIS patients with a single flexible major curve up to $60^{\circ}$, the fusionless PDDC device achieved a satisfactory result as $82 \%$ had residual curves $\leq 30^{\circ}$. These findings suggest that the PDDC device may serve as an alternative to spinal fusion in select patients.

https://thejns.org/doi/abs/10.3171/2019.11.SPINE19827

KEYWORDS fusionless posterior dynamic deformity correction; adolescent idiopathic scoliosis; AIS

$\Lambda$ DOLESCENT idiopathic scoliosis (AIS) is a condition that affects $1 \%-3 \%$ of children $10-16$ years of age..$^{20}$ Mild or moderate curves pose no health threats, but may be associated with body image concerns. Teenagers with mild deformities are placed under clini- cal surveillance and are encouraged to exercise; those with larger curves $\left(>25^{\circ}\right)$ undergo bracing, while skeletally immature patients with curves exceeding $40^{\circ}-45^{\circ}$ are candidates for surgical intervention. ${ }^{4}$ The surgical "gold standard" of AIS management is curve correction with in-

ABBREVIATIONS AIS = adolescent idiopathic scoliosis; IMAST = International Meeting on Advanced Spine Techniques; PDDC = posterior dynamic deformity correction; SRS-22 = Scoliosis Research Society-22. 
strumentation and fusion involving $8-10$ vertebrae. ${ }^{15}$ This traditional approach is an extensive and irreversible surgical procedure that permanently stiffens the adolescent's spine. An intermediate, less-invasive, fusionless procedure may be beneficial for certain patients with AIS. Growth modulating, convex, anterior vertebral body tethering has been developed as a fusionless alternative with results of this technique recently being reported by Newton et al. ${ }^{12,13}$ and Samdani et al. ${ }^{17}$ Tethering necessitates an anterior surgical approach to the spine, which is much less commonly used compared to the posterior approach for the treatment of AIS. As such, there is no intermediate posterior and less-complex surgical approach for AIS.

A novel posterior dynamic deformity correction (PDDC) device (ApiFix Ltd.) was developed to provide a less-invasive, fusionless means of correcting AIS curves and controlling the deformity over time. ${ }^{7}$ This device has a ratchet mechanism that allows unidirectional elongation of an expandable rod that is made of titanium alloy with amorphous diamond-like ceramic coating. The expandable rod, with polyaxial rings (eye joint) at its extremity, is anchored to the spine with 2 pedicle screws that are implanted around the apex of the main curve. This connection should deliver minimal moment to the screwimplant interface and is designed to resist mainly during compression loading. The ratchet mechanism enables both immediate intraoperative curve reduction and potential gradual postoperative curve correction by unidirectional device elongation, which is driven by optional corrective spinal exercises performed by the patient. The implant has a control pin that can abort the ratchet mechanism and, if desired, put the device in a neutral mode or in a locked position to create a fusion-like rod (Fig. 1). In the current design, the total rod excursion is either $30 \mathrm{~mm}$ or $40 \mathrm{~mm}$, depending on the predistraction rod length. Preclinical bench tests and biomechanical characteristics have previously been reported.1,9

The PDDC system was introduced for clinical use in 2012 with the aim to correct moderate Lenke type 1 or type 5 idiopathic curves without fusion. The preliminary outcomes of bridging 3-4 discs in patients with variable curve severity were reported at the 2018 International Meeting on Advanced Spine Techniques (IMAST). ${ }^{8}$ Analysis of the early experience with PDDC demonstrated major curve correction of $32 \%$ only. With further clinical experience it has been observed that utilization of longer PDDC constructs, spanning 5-6 disc levels, yielded better final curve correction. The learning curve with PDDC use, studied by comparing curve correction with short constructs to longer ones, was reported at the 2019 IMAST. ${ }^{5}$ By spanning more levels, $70 \%$ of the patients had a residual curve of less than $35^{\circ}$ at 2 years' follow-up. Following the recent FDA approval of the PDDC system and nearing the introduction of this new technology to the US, refined indications were formulated as follows: Lenke type 1 or type 5 curves up to $60^{\circ}$ that reduce on lateral bending views to $30^{\circ}$ or less and kyphosis of $50^{\circ}$ or less. The purpose of this paper is to examine the outcomes after PDDC surgery spanning 5-6 levels for this subgroup of patients after a minimum 2-year follow-up.

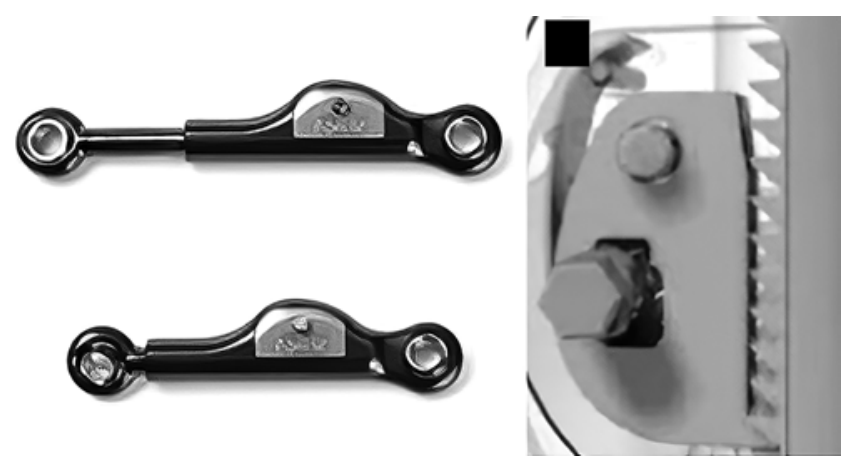

FIG. 1. Left: The PDDC device with (upper) and without (lower) lengthening. Note the eye joints and the control pin. Right: The ratchet mechanism.

\section{Methods}

We conducted a retrospective review of patients treated with PDDC with the following inclusion criteria: single AIS structural curve between $40^{\circ}$ and $60^{\circ}$, curve flexibility $\leq 30^{\circ}$, PDDC surgery spanning 5-6 levels, and a minimum 2-year follow-up. A successful outcome was defined as a curve magnitude of $\leq 30^{\circ}$ at final follow-up. Serious adverse events and reoperations were recorded.

\section{Surgical Technique}

The concave side of the spine was exposed through an incision $15 \mathrm{~cm}$ or greater around the apex of the curve, while the convexity of the spine was left unexposed. Two pedicle screws were inserted at the end vertebrae and connected by eye joints to the PDDC, spanning 5-6 disc spaces. Distraction during surgery was applied in concert with application of manual lateral corrective forces that allowed significant correction of the deformity. No fusion was performed. At approximately $2-3$ weeks after surgery, the patients were directed to start 5 basic Schroth-like exercises with the goal to potentially enable further rod elongation through the ratchet mechanism. The patients were instructed to perform the exercises for 30 minutes daily and were continued for 3-6 months after surgery. No braces were used and no restrictions on physical activities were imposed on the adolescents.

\section{Patient Outcomes}

Patient demographic and radiographic data were evaluated. Patients completed the Scoliosis Research Society-22 $(\mathrm{SRS}-22)^{2}$ questionnaire preoperatively and at 24 months postoperatively. In addition, a numerical questionnaire (score range 1-5) regarding satisfaction with the procedure, would they choose it again, and would they recommend it to a friend, was administered at final follow-up.

\section{Statistical Evaluation}

The Wilcoxon signed-rank test for 2 means (paired observations) was applied for testing the statistical significance of the curve magnitude changes in the postoperative period from the pretreatment curve size. Data were analyzed using the SAS statistical program (version 9.3, SAS Institute). 
TABLE 1. Demographic data, curve types, and coronal and sagittal Cobb angles before and after surgery

\begin{tabular}{|c|c|c|c|c|c|c|c|c|c|c|c|c|}
\hline \multirow{2}{*}{$\begin{array}{l}\text { Case } \\
\text { No. }\end{array}$} & \multirow{2}{*}{$\begin{array}{l}\text { Age (yrs), } \\
\text { Sex }\end{array}$} & \multirow{2}{*}{$\begin{array}{l}\text { Lenke } \\
\text { Curve } \\
\text { Type }\end{array}$} & \multirow{2}{*}{$\begin{array}{l}\text { Risser } \\
\text { Grade }\end{array}$} & \multirow{2}{*}{$\begin{array}{c}\text { Preop } \\
\text { Cobb } \\
\text { Angle }\left(^{\circ}\right)\end{array}$} & \multirow{2}{*}{$\begin{array}{c}\text { Bending } \\
\text { Radiograph } \\
\text { Angle }\left(^{\circ}\right)\end{array}$} & \multicolumn{4}{|c|}{ Cobb Angle $\left({ }^{\circ}\right)$} & \multirow{2}{*}{$\begin{array}{c}\text { Lordo/Kypho } \\
\text { Angle }\left(^{\circ}\right)\end{array}$} & \multirow{2}{*}{$\begin{array}{c}\text { Postop } \\
\text { Lordo/Kyoho } \\
\text { Angle }\left({ }^{\circ}\right)\end{array}$} & \multirow[b]{2}{*}{ FU } \\
\hline & & & & & & Postop & Final & Preop Minor & Final Minor & & & \\
\hline 1 & $13, F$ & 1 & 2 & 51 & 34 & 34 & 36 & 32 & 32 & $46 / 26$ & $43 / 27$ & $30 \mathrm{mos}$ \\
\hline 2 & $13, F$ & 5 & 3 & 42 & 20 & 22 & 23 & 20 & 4 & $48 / 24$ & $45 / 25$ & 3 yrs \\
\hline 3 & $15, \mathrm{~F}$ & 5 & 2 & 41 & 11 & 15 & 17 & 22 & 14 & $45 / 26$ & $45 / 25$ & $2 \mathrm{yrs}$ \\
\hline 4 & $17, \mathrm{~F}$ & 5 & 3 & 45 & 21 & 32 & 35 & 33 & 33 & $52 / 22$ & $47 / 30$ & $2 \mathrm{yrs}$ \\
\hline 5 & $15, \mathrm{~F}$ & 1 & 2 & 47 & 23 & 18 & 19 & 31 & 7 & $50 / 20$ & $47 / 20$ & 3 yrs \\
\hline 6 & $15, \mathrm{~F}$ & 1 & 4 & 50 & 13 & 28 & 28 & 16 & 3 & $55 / 23$ & $50 / 22$ & $2 \mathrm{yrs}$ \\
\hline 7 & $14, \mathrm{~F}$ & 1 & 2 & 40 & 24 & 25 & 23 & 19 & 9 & $45 / 20$ & $46 / 25$ & $2 \mathrm{yrs}$ \\
\hline 8 & $14, \mathrm{~F}$ & 1 & 3 & 44 & 18 & 22 & 21 & 26 & 22 & $40 / 21$ & $38 / 25$ & 2 yrs \\
\hline 9 & $15, F$ & 1 & 4 & 55 & 17 & 25 & 26 & 22 & 12 & $52 / 25$ & $48 / 29$ & $2 \mathrm{yrs}$ \\
\hline 10 & $16, F$ & 1 & 3 & 47 & 24 & 30 & 30 & Missing & 10 & $43 / 28$ & $41 / 25$ & 2 yrs \\
\hline 11 & $16, M$ & 1 & 2 & 47 & 25 & 30 & 27 & 30 & 23 & $42 / 20$ & $44 / 25$ & $2 \mathrm{yrs}$ \\
\hline 12 & $16, F$ & 5 & 4 & 40 & 12 & 22 & 20 & 35 & 25 & $55 / 20$ & $43 / 25$ & 2 yrs \\
\hline 13 & $15, M$ & 1 & 2 & 48 & 22 & 26 & 17 & 16 & 14 & $50 / 27$ & $48 / 28$ & 3 yrs \\
\hline 14 & $15, F$ & 5 & $2-3$ & 48 & 17 & 17 & 15 & 17 & 12 & $55 / 20$ & $45 / 25$ & $2 \mathrm{yrs}$ \\
\hline 15 & $15, F$ & 5 & 3 & 52 & 10 & 20 & 24 & 35 & 26 & $44 / 30$ & $37 / 30$ & 2 yrs \\
\hline 16 & $16, F$ & 1 & 3 & 53 & 26 & 29 & 32 & 29 & 7 & $35 / 31$ & $33 / 37$ & $2 \mathrm{yrs}$ \\
\hline 17 & $16, F$ & 5 & 3 & 50 & 23 & 28 & 24 & 35 & 29 & $42 / 34$ & $40 / 30$ & $2 \mathrm{yrs}$ \\
\hline 18 & $17, M$ & 5 & 3 & 48 & 19 & 26 & 29 & 42 & 28 & $32 / 25$ & $34 / 25$ & $2 \mathrm{yrs}$ \\
\hline 19 & $16, \mathrm{~F}$ & 1 & 4 & 43 & 17 & 23 & 28 & 24 & 17 & $50 / 20$ & $44 / 23$ & 2 yrs \\
\hline 20 & $15, \mathrm{~F}$ & 1 & 4 & 45 & 22 & 28 & 31 & 23 & 22 & $47 / 20$ & $45 / 30$ & $2 \mathrm{yrs}$ \\
\hline 21 & $14, \mathrm{~F}$ & 5 & 3 & 52 & 30 & 24 & 24 & 27 & 23 & $46 / 35$ & $45 / 36$ & $2 \mathrm{yrs}$ \\
\hline 22 & $13, F$ & 1 & 2 & 44 & 20 & 20 & 20 & 31 & 12 & $54 / 25$ & $51 / 30$ & $2 \mathrm{yrs}$ \\
\hline
\end{tabular}

$\mathrm{FU}=$ follow-up; Kypho = kyphosis; Lordo = lordosis.

\section{Results}

Twenty-two patients from 5 medical centers who met the inclusion criteria were identified (Table 1). These patients underwent surgery between June 2015 and December 2016. There were 19 girls and 3 boys, 13-17 years old, with Risser grades $\geq 2$. Thirteen had Lenke type 1 curves and 9 had type 5 curves (Figs. 2 and 3). The mean preoperative curve was $47^{\circ}$ (range $40^{\circ}-55^{\circ}$ ). At a minimum of 2 years of follow-up, the mean final major curve angle measured $25^{\circ}(46 \%$ correction; $\mathrm{p}<0.05)$. In $18(82 \%)$ of 22 patients, the mean final Cobb angle measured $\leq 30^{\circ}$ (range $15^{\circ}-30^{\circ}$ ). Trunk shift was corrected by $1.5 \mathrm{~cm}$ (range $0.4-$ $4.3 \mathrm{~cm}$ ). The mean minor curve was reduced from $27^{\circ}$ to $17^{\circ}$ at final follow-up (35\% correction; $\mathrm{p}<0.05$ ). For Lenke type 1 patterns, mean $2 \mathrm{D}$ thoracic kyphosis was $24^{\circ}$ preoperatively versus $27^{\circ}$ at the final follow-up ( $\left.\mathrm{p}<0.05\right)$, and for Lenke type 5 curves, the mean lumbar lordosis was $47^{\circ}$ preoperatively versus $42^{\circ}$ at the final follow-up $(\mathrm{p}<0.05)$.

The mean preoperative SRS-22 score changed from $2.74 \pm 0.3$ at baseline to $4.31 \pm 0.4$ at 2 years after surgery $(\mathrm{p}<0.0001)$. The mean preoperative self-image score and satisfaction scores increased from preoperative values, while pain, activity, and mental health domain scores did not change significantly. Although statistically significant $(3.14 \pm 0.39$ vs $4.03 \pm 0.41)$, the change in self-image score did not meet the minimum clinically important difference of $0.98 .^{3}$

Pooled results from the 3-question questionnaire (score range 1-5) were as follows: satisfaction with the procedure $=4.8 / 5$, would they choose the procedure again $=$ $4.8 / 5$, and would they recommend it to a friend $=4.8 / 5$.

Four patients $(18 \%)$ underwent revision surgery because of nut loosening $(n=2)$, pedicle screw backup $(n=1)$, and ratchet malfunction $(n=1)$. In 3 patients the implant was retained without the need for fusion and in 1 patient it was removed without curve progression.

\section{Discussion}

Our preliminary experience with a novel and lessinvasive PDDC spanning 3-4 disc spaces in moderate AIS showed that only a modest $32 \%$ curve correction was achieved. ${ }^{8}$ This current study describes the clinical experience gained by using a longer construct that could enable better curve correction and stabilization of AIS without concomitant spinal fusion. The radiographic data obtained at 2-3 years of follow-up in a cohort of individuals with AIS supports the view that PDDC spanning 5-6 motion segments is a valid alternative to traditional instrumentation with fusion. Besides using a longer implant, flexible curves bending to $\leq 30^{\circ}$ were chosen and were considered to be crucial for procedural success. The main curves 

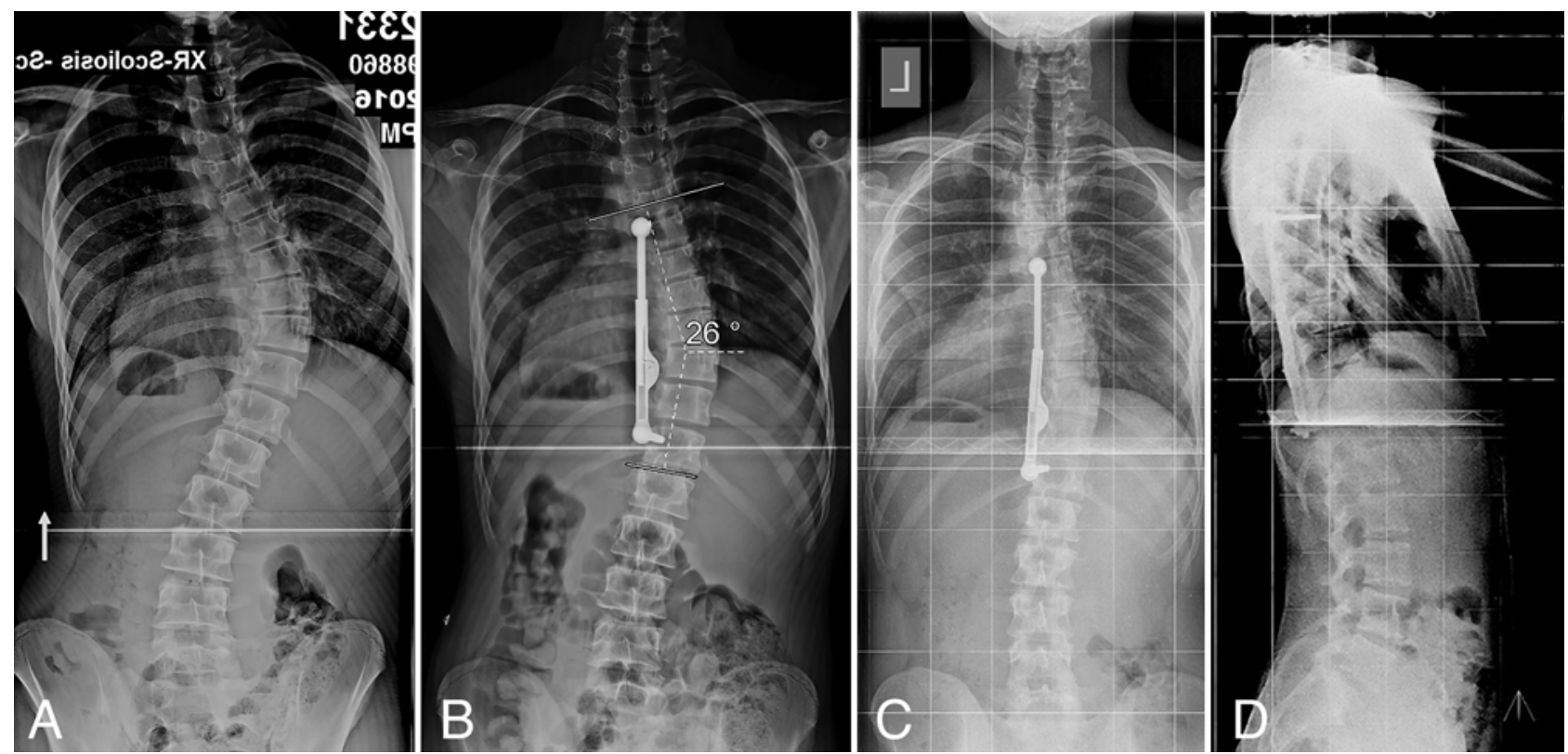

FIG. 2. Case 13. Standing radiographs of a 15 -year-old boy with a Lenke type 1 curve. A: The preoperative curve was $48^{\circ}$.

B: Immediately after surgery the curve was reduced to $26^{\circ}$. C and D: At the 3-year follow-up, the curve measures $17^{\circ}$ and there is a slight, positional, shoulder-height difference.

were reduced by $46 \%$, and curve reduction was maintained during the observation period of 2-3 years. In 18 of 22 patients ( $82 \%$ of the cohort) the final Cobb angle of the major curve did not exceed $30^{\circ}$. Keeping the major Cobb angle under $30^{\circ}$ may enable future removal of the dynamic device without the danger of postremoval curve progression. Concomitantly, with reduction of the major curve, the secondary curves were also reduced by an average of $35 \%$. The results obtained in flexible curves with instrumentation spanning 5-6 disc levels provided far better curve correction than was obtained with shorter con- structs spanning only 3-4 disc levels. Surgery with longer constructs did not change the minor invasive nature of the procedure, ensuring very short hospitalization and recovery. The results obtained are comparable to those achieved with formal fusion without the need to sacrifice spinal motion and with a less-invasive nature, with the potential to ensure prompt recovery.

While Lenke type 1 curves were referred to surgery if the deformity exceeded $40^{\circ}-45^{\circ}$, Lenke type 5 curves were operated on with a lower Cobb angle threshold because of the reported tendency of thoracolumbar curves
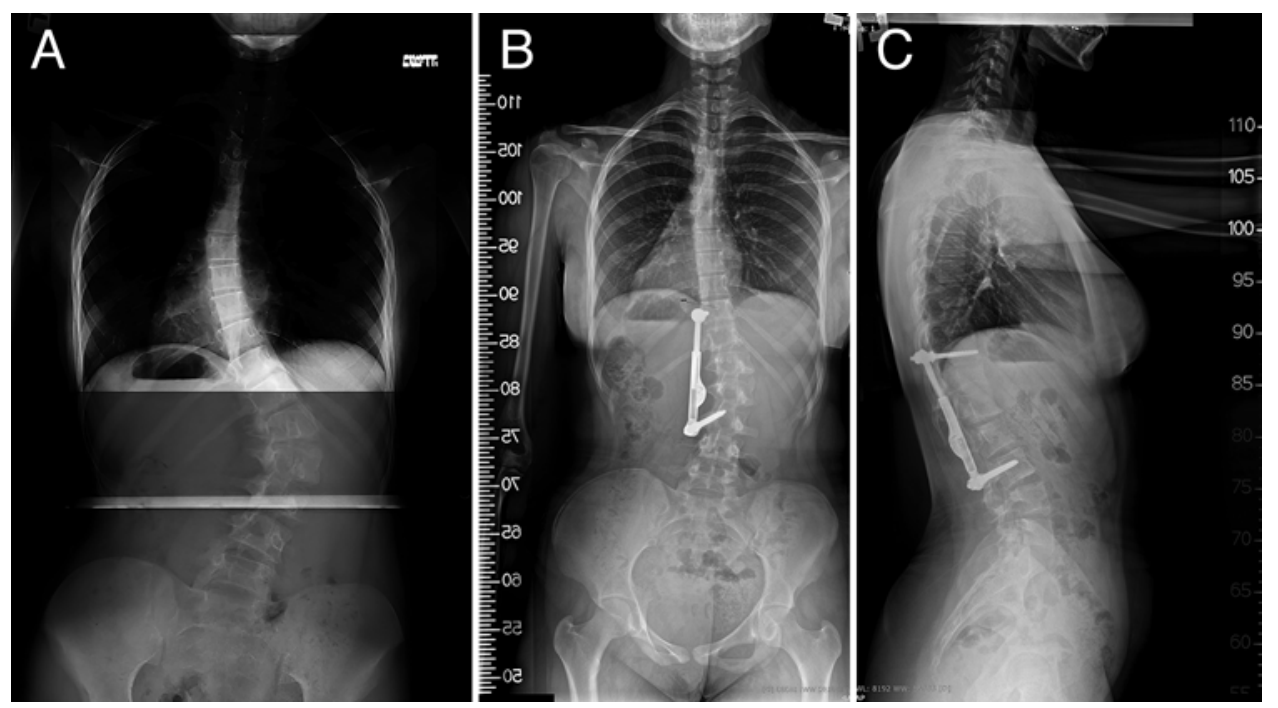

FIG. 3. Case 21. Standing radiographs of a 14 -year-old girl with a Lenke type 5 curve of $52^{\circ}(\mathbf{A})$ reduced to $23^{\circ}$ at the 2 -year follow-up (B and C). 
above $35^{\circ}$ to progress even after skeletal maturity, ${ }^{14}$ and also because of the marked trunk imbalance common in this type of deformity. ${ }^{18}$ Although 5 patients were Risser grade 4 at the time of surgery, they either had a progressive curve or were displeased with their body image. This technique enabled correction of the trunk shift as well as significant Cobb angle reduction. All participants reached skeletal maturity at the end of the follow-up period of this study; however, long-term follow-up is required to determine if there is any curve progression in the future. Longer-term follow-up will also better assess the possibility of a crankshaft phenomenon in younger skeletally immature patients. Initially, significant emphasis was put on activation of the ratchet mechanism and rod elongation by the performance of postoperative Schroth-like exercises. Per patient self-reporting, all patients who underwent operations were engaged in performing the exercises after surgery, resulting in rod lengthening in many. We have also observed that the ratchet can be activated by daily activities and not only by performing specific exercises. With the recent modified operative strategy in which maximal intraoperative correction is realized, the exercises contribute less to the final curve reduction, yet they may be important in reduction and control of the secondary curves. Nevertheless, in a few patients in the current series, $2^{\circ}-5^{\circ}$ of additional curve correction was achieved following the Schroth-like exercises (Fig. 2). This generally occurred within the first 3-6 months postoperatively. We acknowledge that the primary goal of this device is to prevent the progression of scoliosis over time and that the potential for further correction over time through the ratcheting mechanism is still not fully known. With the current technique of maximizing intraoperative correction, the physical therapy exercises may not be as important as initially conceived and require further study.

The secondary curves were spontaneously reduced concomitantly with major curve reduction, and the correction was maintained throughout the observation period. No "adding on" was observed during follow-up. Previous publications on selective thoracic instrumentation in Lenke type 1 curves have documented that the secondary curves undergo spontaneous correction, and that the correction is maintained in both short- and long-term followup for as long as 20 years..$^{10,11}$

A statistically significant change was noted in the sagittal profile of the spine after surgery. However, this change had no clinical significance. While the thoracic kyphosis was increased in patients with Lenke type 1 deformity, the lumbar lordosis was decreased in Lenke type 5 curves. As previously noted, this change, although statistically significant, had no clinical bearing as the sagittal vertical axis remained in the "normal" range.

The mean preoperative SRS-22 score improved significantly at final follow-up. In particular, the mean preoperative self-image score change was statistically significant, but it did not reach a level of clinical significance. ${ }^{3}$ Patient satisfaction assessed by a questionnaire showed a high satisfaction score (4.8/5). Patients were satisfied with their appearance as reflected in their response to their general satisfaction with the procedure, and the fact that they would recommend the procedure to a friend. In addition, there was also an improvement in the trunk shift by an average of $1.5 \mathrm{~cm}$.

The PDDC device is intended to function as a dynamic implant, allowing motion approximating the natural spine mobility mitigating the occurrence of spontaneous fusion. The radiographs were specifically evaluated for the presence of spontaneous fusion and there was none seen. We realize that radiographic analysis is not $100 \%$ accurate for the assessment of fusion; however, CT evaluation poses the risk of additional radiation exposure, and surgical exploration is too invasive to be used routinely. During the reoperation procedures, no concave fusion was observed. Further study assessing the flexibility of instrumented segments would be of interest. The biomechanical properties of this device were investigated in vitro by Holewijn et al. ${ }^{9}$ They performed a biomechanical study on cadaveric thoracic spines in which they compared spinal motion with the dynamic device versus standard rigid pedicle screw fixation. In a cadaveric spine the ratchet device resulted in only a $40 \%$ decrease in range of motion in flexion/extension compared to a noninstrumented spine. There was only an $18 \%$ reduction in lateral bending, while the range of motion in axial rotation remained unaffected as compared to a noninstrumented spine. In comparison, a full pedicle screw instrumentation, similar to a spinal fusion, resulted in a significantly larger decrease in range of motion in flexion/extension ( $81 \%$ decrease), lateral bending (75\% decrease), and axial rotation (71\% decrease; $\mathrm{p}<$ 0.05). That study demonstrated that spinal range of motion was significantly less constrained by the PDDC device as compared to rigid pedicle screw-rod instrumentation. ${ }^{9}$ Therefore, the device should enable scoliosis correction with preservation of a more physiological spinal motion. Holewijn et al. ${ }^{9}$ also determined that adjacent spinal segment biomechanics were not significantly altered by this device and that these beneficial biomechanical characteristics can be attributed to the polyaxial connectors between the implant and screws. Therefore, the risk of implant failure is deemed low as implant loads in the absence of spinal fusion are expected to be minimal.

Posterior instrumentation and fusion significantly affect postoperative spinal motion and trunk mobility. The restriction is in flexion/extension lateral bending and axial rotation. ${ }^{6,19}$ One important advantage of the posterior dynamic deformity correction device is that the implant preserves spinal motion. The preservation of spinal motion in Lenke type 5 curves is a particularly important advantage of the PDDC because the standard surgical procedure mandates fusion of most of the lumbar motion segments. The preservation of spinal motion may prevent future occurrence of adjacent disc degeneration, pain, and the need for further surgical intervention.

Previous work compared the outcome in patients undergoing instrumentation with PDDC spanning 3-4 levels with a group of AIS patients, in which the major curve was reduced to $35^{\circ}$ on bending views and in which a longer PDDC was used spanning more disc levels. ${ }^{5}$ It was found that only $42 \%$ of the short implant group achieved a correction to $35^{\circ}$ or less, compared to the $70 \%$ success rate in the group with implants spanning 5-6 disc levels.

The ultra long-term consequences of having a spinal 
implant across several disc levels without fusion is unknown at present. The main concern is future screw or implant fracture, or screw loosening. The standard practice of treating patients with AIS is spinal fusion, which is expected to last the lifetime of the individual. Based on the work performed by Rohlmann et al., ${ }^{16}$ we know that the metal construct of a fusion system is under significant loads after bone fusion is achieved; however, as a portion of the load is relieved by the bone fusion, these loads are below the level that leads to system failure. The uniqueness of the PDDC system is its polyaxial joints that do not transfer moments to the screw-bone interface and let the spine take a significant portion of the loads. If the remaining loads are below the level that leads to system failure, then the long-term survival of this system should be similar to that of fusion constructs. Preclinical bench testing of the PDDC system showed that the system was able to hold $700 \mathrm{~N}$ for 10 million cycles; this value is significantly higher than the values with a standard fusion system. ${ }^{1}$ Therefore, the rate of implant failure is predicted to be extremely low. The ultimate goal of the system is to reduce the curve to a point that system removal after several years of serving as an internal brace would not result in curve recurrence or progression. Surgical intervention with the system in patients with low Risser grades (0-1) with curve reduction to $25^{\circ}$ or lower may enable safe removal of the implant after skeletal maturity. Additional work and longer follow-up are required to assess the ability of this novel system to achieve this long-term goal.

Four severe adverse events were encountered in the present series. In 2 instances nut loosening occurred in the early postoperative course. Nut loosening was attributed to insufficient torque while tightening the nuts. As a result, currently, more torque is applied during nut tightening. In 1 case, ratchet malfunction allowing rod shortening occurred 3 years after surgery. The residual curve did not progress after removal of the implant without further action. The implant was retained in 3 of 4 patients undergoing revision surgery.

The limitations of our study were the small cohort and the retrospective outcomes evaluation. Nevertheless, the radiographic and patient outcomes are encouraging.

\section{Conclusions}

In AIS patients with a single flexible major curve up to $60^{\circ}$, the fusionless PDDC device achieved a satisfactory result as $82 \%$ had residual curves $\leq 30^{\circ}$. These findings suggest that the PDDC device may serve as an alternative to spinal fusion in select patients.

\section{References}

1. Arnin U, El-Hawary R, Betz RR, Lonner BS, Floman Y: Preclinical bench testing on a novel posterior dynamic scoliosis correction device for scoliosis. Spine Deform 7:203-212, 2019

2. Asher M, Min Lai S, Burton D, Manna B: Scoliosis research society-22 patient questionnaire: responsiveness to change associated with surgical treatment. Spine (Phila Pa 1976) 28:70-73, 2003

3. Carreon LY, Sanders JO, Diab M, Sucato DJ, Sturm PF, Glassman SD: The minimum clinically important difference in Scoliosis Research Society-22 Appearance, Activity, And Pain domains after surgical correction of adolescent idiopathic scoliosis. Spine (Phila Pa 1976) 35:2079-2083, 2010

4. de Kleuver M, Lewis SJ, Germscheid NM, Kamper SJ, Alanay A, Berven SH, et al: Optimal surgical care for adolescent idiopathic scoliosis: an international consensus. Eur Spine J 23:2603-2618, 2014

5. El-Hawary R, Betz RR, Lonner BS, Floman Y: Optimization of outcomes with a novel fusionless posterior dynamic deformity correction (PDDC) device for adolescent idiopathic scoliosis: learning curve drives indications, in IMAST 2019 Amsterdam. 26th International Meeting on Advanced Spine Techniques. Final Program. Milwaukee: Scoliosis Research Society, 2019, p 158 (Abstract 180)

6. Engsberg JR, Lenke LG, Uhrich ML, Ross SA, Bridwell KH: Prospective comparison of gait and trunk range of motion in adolescents with idiopathic thoracic scoliosis undergoing anterior or posterior spinal fusion. Spine (Phila Pa 1976) 28:1993-2000, 2003

7. Floman Y, Burnei G, Gavriliu S, Anekstein Y, Straticiuc S, Tunyogi-Csapo M, et al: Surgical management of moderate adolescent idiopathic scoliosis with ApiFix $\AA$ : a short periapical fixation followed by post-operative curve reduction with exercises. Scoliosis 10:4-9, 2015

8. Floman Y, Gavriliu S, Potaczek T, Zarzycki D, Desai B, Tunyogi-Csapo M, et al: A new posterior dynamic device for correction of moderate adolescent idiopathic scoliosis: 27 cases with two to five years of follow up, in IMAST 2018 Los Angeles. 25th International Meeting on Advanced Spine Techniques. Final Program. Milwaukee: Scoliosis Research Society, 2018, pp 101-102 (Abstract 61)

9. Holewijn RM, de Kleuver M, van der Veen AJ, Emanuel KS, Bisschop A, Stadhouder A, et al: A novel spinal implant for fusionless scoliosis correction: a biomechanical analysis of the motion preserving properties of a posterior periapical concave distraction device. Global Spine J 7:400-409, 2017

10. Larson AN, Fletcher ND, Daniel C, Richards BS: Lumbar curve is stable after selective thoracic fusion for adolescent idiopathic scoliosis: a 20-year follow-up. Spine (Phila Pa 1976) 37:833-839, 2012

11. Lenke LG, Betz RR, Bridwell KH, Harms J, Clements DH, Lowe TG: Spontaneous lumbar curve coronal correction after selective anterior or posterior thoracic fusion in adolescent idiopathic scoliosis. Spine (Phila Pa 1976) 24:16631672,1999

12. Newton PO, Fricka KB, Lee SS, Farnsworth CL, Cox TG, Mahar AT: Asymmetrical flexible tethering of spine growth in an immature bovine model. Spine (Phila Pa 1976) 27:689-693, 2002

13. Newton PO, Kluck DG, Saito W, Yaszay B, Bartley CE, Bastrom TP: Anterior spinal growth tethering for skeletally immature patients with scoliosis: a retrospective look two to four years postoperatively. J Bone Joint Surg Am 100:16911697,2018

14. Pesenti S, Jouve JL, Morin C, Wolff S, Sales de Gauzy J, Chalopin A, et al: Evolution of adolescent idiopathic scoliosis: results of a multicenter study at 20 years' follow-up. Orthop Traumatol Surg Res 101:619-622, 2015

15. Robitaille M, Aubin CE, Labelle H: Intra and interobserver variability of preoperative planning for surgical instrumentation in adolescent idiopathic scoliosis. Eur Spine J 16:16041614,2007

16. Rohlmann A, Graichen F, Weber U, Bergmann G: 2000 Volvo Award winner in biomechanical studies: Monitoring in vivo implant loads with a telemetrized internal spinal fixation device. Spine (Phila Pa 1976) 25:2981-2986, 2000

17. Samdani AF, Ames RJ, Kimball JS, Pahys JM, Grewal H, Pelletier GJ, et al: Anterior vertebral body tethering for id- 
iopathic scoliosis: two-year results. Spine (Phila Pa 1976) 39:1688-1693, 2014

18. Souder C, Newton PO, Shah SA, Lonner BS, Bastrom TP, Yaszay B: Factors in surgical decision making for thoracolumbar/lumbar AIS: it's about more than just the curve magnitude. J Pediatr Orthop 37:e530-e535, 2017

19. Udoekwere UI, Krzak JJ, Graf A, Hassani S, Tarima S, Riordan M, et al: Effect of lowest instrumented vertebra on trunk mobility in patients with adolescent idiopathic scoliosis undergoing posterior spinal fusion. Spine Deform 2:291-300, 2014

20. Weinstein SL, Dolan LA, Cheng JCY, Danielsson A, Morcuende JA: Adolescent idiopathic scoliosis. Lancet 371:1527-1537, 2008

\section{Disclosures}

Dr. Floman is a co-founder of ApiFix. Dr. El-Hawary reports being a consultant for Medtronic Canada, DePuy Synthes Spine, ApiFix Ltd., Globus Medical, and Wishbone Medical, and holding stock options in ApiFix Ltd. and Wishbone Medical. Dr. Millgram reports having direct stock ownership in ApiFix. Dr. Lonner reports being a consultant to DePuy Synthes, Ethicon, Zimmer Biomet, and ApiFix; having direct stock ownership in Spine Search and Paradigm Spine; having private investments in Paradigm Spine; serving on the Scientific Advisory Board, Speaker's Bureau, and receiving royalties from DePuy Synthes for the development of the Expedium Plus Implant System; serving as a Scientific Advisory Board Member for ApiFix; serving on the Board of Directors of Spine Search and the Setting Scoliosis Straight Foundation; and serving on the Speaker's Bureau for K2M. Dr. Betz reports being a consultant for ApiFix, DePuy Synthes Spine, Globus Medical, SpineGuard, and Wishbone Medical; having stock options in Abyrx, ApiFix, Electrocore, Medovex, Orthobond, SpineGuard, and Wishbone Medical; receiving royalties from DePuy Synthes Spine, Globus Medical, SpineGuard, and Thieme Medical Publishers; serving on the Speakers Bureau for DePuy Synthes Spine and Globus Medical; and having a child who is employed by DePuy Synthes Spine.

\section{Author Contributions}

Conception and design: Floman. Acquisition of data: Floman, Millgram. Analysis and interpretation of data: all authors. Drafting the article: Floman, El-Hawary, Lonner, Betz. Critically revising the article: all authors. Reviewed submitted version of manuscript: Floman, El-Hawary, Millgram, Lonner. Approved the final version of the manuscript on behalf of all authors: Floman.

\section{Correspondence}

Yizhar Floman: Assuta Hospital, Tel Aviv, Israel. yizharfloman@ gmail.com. 